\title{
Associations between self-reported sensory impairment and risk of cognitive decline and impairment in the Health and Retirement Study cohort
}

DOI:

10.1093/geronb/gbz043

\section{Document Version \\ Accepted author manuscript}

Link to publication record in Manchester Research Explorer

Citation for published version (APA):

Maharani, A., Dawes, P., Nazroo, J. Y., Tampubolon, G., Pendleton, N., \& Sense-Cog (2019). Associations between self-reported sensory impairment and risk of cognitive decline and impairment in the Health and Retirement Study cohort. Journals of Gerontology. Series B: Psychological Sciences \& Social Sciences. https://doi.org/10.1093/geronb/gbz043

Published in:

Journals of Gerontology. Series B: Psychological Sciences \& Social Sciences

\section{Citing this paper}

Please note that where the full-text provided on Manchester Research Explorer is the Author Accepted Manuscript or Proof version this may differ from the final Published version. If citing, it is advised that you check and use the publisher's definitive version.

\section{General rights}

Copyright and moral rights for the publications made accessible in the Research Explorer are retained by the authors and/or other copyright owners and it is a condition of accessing publications that users recognise and abide by the legal requirements associated with these rights.

\section{Takedown policy}

If you believe that this document breaches copyright please refer to the University of Manchester's Takedown Procedures [http://man.ac.uk/04Y6Bo] or contact uml.scholarlycommunications@manchester.ac.uk providing relevant details, so we can investigate your claim.

\section{OPEN ACCESS}


Title : Associations between self-reported sensory impairment and risk of cognitive decline and impairment in the Health and Retirement Study cohort

Author : Asri Maharani, $\mathrm{PhD}^{1}$, Piers Dawes, $\mathrm{PhD}^{2}$, James Nazroo, $\mathrm{PhD}^{3}$, Gindo

Tampubolon, $\mathrm{PhD}^{3}$ and Neil Pendleton, $\mathrm{PhD}^{1}$ on behalf of the Sense-Cog WP1 group

Corresponding author: Asri Maharani

Address: Humanities Bridgeford Street Building G21, Oxford Road, Manchester M13 9PL, United Kingdom

Telephone: +4416157025

Email address: asri.maharani@manchester.ac.uk

\section{Author affiliation and qualification:}

1 Division of Neuroscience and Experimental Psychology, School of Biological Sciences, Faculty of Biology, Medicine and Health, University of Manchester, Manchester Academic Health Science Centre, Manchester M13 9PL, United Kingdom

2 Division of Human Communication, Development \& Hearing, University of Manchester, Oxford Road, Manchester M13 9PL, United Kingdom

3 Sociology and Cathie Marsh Institute for Social Research, University of Manchester Humanities Bridgeford Street Building, Oxford Road, Manchester M13 9PL, United Kingdom

Number of references: 50

Number of tables: 2

Number of figures: 3

Acknowledgement: 
The Sense-Cog WP1 group are Geir Bertelsen ${ }^{1,2}$, Suzanne Cosh $^{3}$, Audrey Cougnard-Grégoire ${ }^{3}$, Cécile Delcourt $^{3}$, Fofi Constantinidou ${ }^{4}$, Catherine Helmer $^{3}$, M. Arfan Ikram ${ }^{5,6}$, Caroline CW Klaver ${ }^{5,7}$, Iracema Leroi ${ }^{8}$, Magda Meester-Smor ${ }^{5,7}$, Unal Mutlu ${ }^{5,7}$, Virginie Nael ${ }^{3,9,10}$, Henrik Schirmer ${ }^{11}$, Henning Tiemeier ${ }^{5,12}$, Therese von Hanno ${ }^{13,14}$.

1: UiT The Arctic University of Norway, Department of Community Medicine, Faculty of Health Sciences, N-9037 Tromsø, Norway

2: University Hospital of North Norway, Department of Ophthalmology, N-9038 Tromsø, Norway

3: Univ. Bordeaux, Inserm, Bordeaux Population Health Research Center, team LEHA, UMR 1219, F-33000 Bordeaux, France

4: University of Cyprus, Department of Psychology \& Center for Applied Neuroscience, Nicosia, Cyprus

5: Erasmus Medical Centre, Department of Epidemiology, Rotterdam, The Netherlands

6: Erasmus Medical Centre, Departments of Neurology and Radiology, Rotterdam, The Netherlands

7: Erasmus Medical Centre, Department of Ophthalmology, Rotterdam, The Netherlands

8: University of Manchester, Division of Neuroscience and Experimental Psychology, School of Biological Sciences, Manchester, UK

9: Sorbonne University, UMPC University of Paris 06, INSERM, CNRS, Vision Institute, F-75012 Paris, France

10: R\&D Life and Vision Science, Essilor International, F-75012 Paris, France

11: UiT-The Arctic University of Norway, Department of Clinical Medicine, Cardiovascular research Group-UNN, N-9037 Troms $\varnothing$, Norway

12: Erasmus Medical Centre, Department of Psychiatry, Rotterdam, The Netherlands 
13: UiT-The Arctic University of Norway, Department of Clinical Medicine, Faculty of Health Sciences, N-9037 Troms $\varnothing$, Norway

14: Nordland Hospital, Department of Ophthalmology, N-8092 Bodø, Norway

\section{Funding source:}

This work was supported by SENSE-Cog project. This project has received funding from the European Union's Horizon 2020 research and innovation programme under grant agreement No 668648. PD is supported by the NIHR Manchester Biomedical Research Centre.

\section{Conflict of interest:}

The authors have no financial or any other kind of personal conflicts with this paper. 


\section{ABSTRACT}

Objectives: We aimed to determine whether self-assessed single (hearing or visual) and dual sensory (hearing and visual) impairments are associated with cognitive decline and incident possible Cognitive Impairment, No Dementia (CIND) and probable dementia.

Method: Data were drawn from the 1996-2014 surveys of the Health and Retirement Study (HRS), involving 19,618 respondents who had no probable dementia and who were aged 50 years or older at the baseline. We used linear mixed models to test the association between self-assessed sensory impairment and cognitive decline followed by a Cox proportional hazard model to estimate the relative risk of incident possible CIND and probable dementia associated with the presence of sensory impairment.

Results: Respondents with self-assessed single and dual sensory impairment performed worse in cognitive tests than those without sensory impairment. The fully adjusted incidence of developing possible CIND was $17 \%$ higher for respondents with hearing impairment than those without hearing impairment. Respondents with visual impairment had 35\% and 25\% higher risk for developing possible CIND and probable dementia, respectively, than those without visual impairment. Respondents with dual sensory impairment at baseline were $38 \%$ and $26 \%$ more likely to develop possible CIND and probable dementia, respectively, than those with no sensory impairment.

Discussion: Self-assessed sensory impairment is independently associated with cognitive decline and incident possible CIND and probable dementia. Further studies are needed to identify the mechanism underlying this association and to determine whether treatment of sensory impairment could ameliorate cognitive decline and delay the onset of dementia among older adults. 
Keywords: hearing impairment, visual impairment, cognitive decline, longitudinal analysis 


\section{Introduction}

Population ageing has resulted in a notable epidemiological transition marked by an increase in the prevalence of chronic diseases, including dementia and sensory (hearing and/or visual) impairment. In 2015, there were over 46.8 million individuals aged 60 years and older living with dementia (Prince et al., 2015); this number is projected to increase to 72 million by the year 2050 (Ahmadi-Abhari et al., 2017), placing a substantial burden on healthcare in terms of disability and health costs. The increase in disability-adjusted life years attributed to dementia is among the largest for any disease, soaring $113 \%$ from 4.7 million in 1990 to 10 million in 2010 (Prince et al., 2015). The global cost of dementia reached $\$ 818$ billion USD in 2015 , with $85 \%$ of that sum related to family and social needs (Prince et al., 2015). This extraordinary burden has made prevention and treatment of dementia a public health priority. The absence of disease-modifying treatments for any common dementia lends a particular urgency to the need to identify modifiable risk and protective factors that can prevent or delay dementia onset, decreasing the burden of this disease (Livingston et al., 2017).

Sensory (hearing and/or visual) impairments are chronic conditions that are also associated with ageing. The World Health Organization (WHO) estimates that one third of people over 65 years of age are affected by disabling hearing loss (WHO, 2017a) and that $81 \%$ of all people who are blind or have moderate to severe vision impairment are aged 50 years or above (WHO, 2017b). Sensory impairment is one of the modifiable factors of ageing, and addressing it may protect against dementia. Sensory impairment has been reported to be associated with cognitive decline (Lin et al., 2004; Lindenberger \& Baltes, 1994; Maharani, Dawes, Nazroo, Tampubolon \& Pendleton, 2018; Yamada et al., 2015), which is the hallmark of dementia, but a limited number of epidemiological studies have assessed the relation between sensory impairment and dementia. For example, a study using data from a Baltimore 
Longitudinal Study of Aging cohort found that the severity of baseline hearing loss was associated with an increased risk of all-cause dementia and Alzheimer disease (Lin et al., 2011). A more recent study on older people aged 70-79 years reported that respondents with moderate or severe hearing impairment were at an increased risk of 9-year incident dementia (Deal et al., 2017).

Only limited numbers of studies have examined the effect of visual and dual sensory impairment on cognitive decline and dementia and the findings were mixed. For example, Hong et al. (2016) found that the presence of hearing, visual and dual sensory impairments were not associated with lower Mini-Mental State Examination (MMSE) over five years (Hong, Mitchell, Burlutsky, Liew, \& Wang, 2016). Differently, in a sample of 6,112 women aged 69 and older from the Study of Osteoporotic Fractures, visual impairment, but not hearing impairment, was associated with an increase in the likelihood of cognitive decline; dual sensory impairment was associated with the greatest odds of cognitive decline (Lin et al., 2004). A report from "Sensory and Motor Dysfunctions in Aging and AD" workshop held by the National Institute on Aging stated that olfactory, hearing and vision functioning changes increased risk of developing Alzheimer's Disease (Albers et al., 2015). Our prior study, using three nationally representative longitudinal data sets from the United States and Europe, found that the negative association between sensory impairment and cognitive ability was greater for respondents with dual sensory impairment than for those with single (hearing or visual) impairment (Maharani, Dawes, Nazroo, Tampubolon \& Pendleton, 2018). This finding was supported by a study on nursing home residents which reported that residents with dual sensory impairment experienced steeper cognitive decline than those with a single impairment or no impairment (Yamada et al., 2015). Livingston and colleagues developed a life course model of dementia risk factors and estimated that about $9 \%$ of dementia cases are attributable to hearing loss in midlife (Livingston et al., 2017), yet visual and dual (hearing 
and visual) impairments were not included in their model mainly due to the lack of robust evidence.

In spite of the significant amount of effort invested in describing an association between sensory impairment and cognitive performance among the older population, little evidence on the nature of that relationship has become available. Several hypotheses as to how sensory impairment relates to cognitive function have been postulated. The first hypothesis is the 'cognitive load on perception' hypothesis, according to which cognitive decline may lead to apparent declines in sensory performance because cognitive declines reduce the cognitive resources available for sensory perception (Humes, Busey, Craig, \& Kewley-Port, 2013; Lindenberger \& Baltes, 1994). Speech recognition among individuals with hearing impairment becomes more challenging, which may lead to increased perceptual load and cognitive load compared to those with normal hearing function. According to the framework for understanding effortful listening (FUEL), listening effort also depends on the motivation of the listener to spend their mental effort to keep listening in any situation (Pichora-Fuller et al., 2016). Second is the 'sensory deprivation' hypothesis, according to which sensory loss may cause cognitive decline in later life as cognitive decline reflects the effect of reduced sensory stimulation (Lin et al., 2013; Lindenberger \& Baltes, 1994; Wahl \& Heyl, 2003). Third is the 'common cause' hypothesis, which states that correlations of sensory functioning and cognitive ability may increase due to common age-related change factors (Lindenberger \& Baltes, 1994). The fourth hypothesis is that individuals with sensory impairment may be disadvantaged in their performance on psychometric tests as a direct result of difficulties in sensory perception (Lindenberger \& Baltes, 1994; Van Boxtel, Ten Tusscher, Metsemakers, Willems, \& Jolles, 2001). Describing and understanding trajectories of cognitive decline and how these relate to sensory impairment may offer insight into the dynamics of cognitive 
decline and identify opportunities for intervention to maximise cognitive function and longevity in older age.

The objectives of the present study were to identify the association between sensory impairment and cognitive decline and to elucidate the relationship between sensory impairment and the development of possible Cognitive Impairment, No Dementia (CIND) and probable dementia. The study extends previous research examining the association between sensory impairment and the risk of possible CIND and probable dementia by using a nationally representative study population, engaging in a longer follow-up period, including more risk factors, and examining hearing, visual and dual sensory impairment.

\section{Methods}

This study forms part of the SENSE-Cog multi-phase research programme, funded by the European Union Horizon 2020 programme. SENSE-Cog aims to promote mental well-being in older adults with sensory and cognitive impairments (http://www.sense-cog.eu/). The first work package of this project aims to better understand the links between sensory, cognitive and mental ill-health in older Europeans.

\section{Data and study sample}

Data were drawn from Waves 3 (1996) to 12 (2014) of the Health and Retirement Study (HRS) (Sonnega et al., 2014). The HRS is a prospective cohort study of approximately 20,000 adults aged 50 or older with primary residence in the United States (US). Data collection included sociodemographic information, lifestyle, health and cognition. The HRS was conducted by the University of Michigan and supported by the National Institute on Aging and the Social Security Administration. Using a panel design, the HRS interviewed the same respondents every 2 years, and added new respondents to the sample every 6 years to 
replenish the sample and adjust for aging and attrition. The first wave of the HRS was conducted in 1992 with a cohort composed of individuals born between 1931 and 1941. In the following year, this original cohort was merged with a much older cohort, the Study of Assets and Health Dynamics among the Oldest Old (AHEAD) cohort, which was born in or before 1923. Two additional cohorts, the so-called Children of the Depression Age cohort (CODA), born between 1924 and 1930, and the War Babies cohort, born between 1942 and 1947, were added in 1998.

Our study sample consisted of all HRS respondents aged 50-98 years old at baseline who had normal cognitive function at baseline, and for whom there was information on sensory function who participated in Wave $3(8,419$ respondents) as well as in the refreshment samples in Waves 4 (4,040 respondents), 7 (2,516 respondents) and 10 (4,643 respondents). The selection procedure of the sample included in this study is illustrated in Appendix 1 . Respondents were categorised as having normal cognitive function at baseline if they had a score from 12 to 27 on the Telephone Interview for Cognitive Status (TICS) (Langa, Kabeto \& Weir, 2010). All respondents provided written informed consent and the HRS was approved by the Health Sciences and Behavioral Sciences institutional review board at the University of Michigan.

\section{Evaluation of cognitive functions and diagnosis of dementia}

The HRS Waves 3-12 assess cognitive function in respondents with tests adapted from the Telephone Interview for Cognitive Status (TICS); they include episodic memory, serial of 7 subtraction, and counting backward tests (Castanho et al., 2014; Langa et al., 2017). In the episodic memory test, the interviewer reads a list of 10 simple nouns to the participants and asks them to recall as many words as possible, both immediately and after a 5 minutes delay (after asking other survey questions). The raw total scores of the immediate and delayed tests 
combined correspond to the number of words that the participants recall, ranging from 0 to 20. In the serial 7s test, participants are asked to count down from 100 by 7 for a total of five trials. The resulting raw total score ranges from 0 to 5 . In the counting backward test, the interviewer asks participants to count backwards for 10 continuous numbers beginning with the number 20. The scores for this range from 0 to 2 ( 0 if incorrect on first and second try; 1 point if correctly answered on second try; 2 points if answered correctly on first try). To measure general cognitive function, we used the composite scores of episodic memory, serial of 7 subtraction, and counting backward tests, which can range from 0 to 27 .

To define cognitive status which includes probable dementia diagnosis, we used score cutoffs developed by Langa and Weir (Langa, Kabeto \& Weir, 2010), who categorised those scoring 0 to 6 points on the 27-point TICS scale as having probable dementia, 7 to 11 as having possible CIND, and 12 to 27 as having normal cognitive function. Crimmins et al. further evaluated these cut-off points against the prevalence of dementia and CIND in the Aging, Demographics, and Memory Study (ADAMS) (Crimmins, Kim, Langa \& Weir, 2011).

Sensory function

The presence of sensory impairment was identified using self-reported assessments of hearing and visual function. Self-reported hearing function data were collected using the question: 'Is your hearing [using a hearing aid as usual] excellent (1), very good (2), good (3), fair (4) or poor (5)?'. Data on visual function were collected using the question: 'Is your eyesight [using glasses or corrective lens as usual] excellent (1), very good (2), good (3), fair (4) or poor (5)?'. The self-reported question for visual function has been validated elsewhere (Whillans \& Nazroo, 2014). Following Whillans and Nazroo (2014) and extending their work to hearing impairment, we identified respondents as having hearing or visual impairment if 
they reported having fair or poor hearing or vision. We further categorised sensory impairment in the simultaneous model into: no impairment, single (vision or hearing) sensory impairment, and dual sensory impairment (impairment in both senses).

\section{Covariates measurements}

Sociodemographic information includes age (years), gender, marital status (married or cohabiting and not married), educational level completed (less than high school, high school, or college) and wealth (three categories: poorest, middle, and wealthiest representing income). We included a birth cohort variable in the analysis by grouping the sample into three birth cohorts based on sociohistorical events having occurred in the United States: prewar cohort (those who were born before the start of World War II in 1938), the war cohort (1939-1945), and post-war cohort (born after 1946) (Tampubolon \& Maharani, 2017). Incident dementia is known to be affected by health behaviour and health status (Anstey, von Sanden, Salim \& O’Kearney, 2007; Laurin, Verreault, Lindsay, MacPherson \& Rockwood, 2001; Weuve et al., 2004; Yaffe, 2013). Health behaviour covariates include smoking habits, drinking behaviour, and physical exercise. Smoking habits were categorised as current smoker, past smoker and non-smoker, while drinking behaviour was defined in units per week. Regular exercise was defined as engaging in vigorous physical activity more than three times a week during leisure time. Health conditions are captured using the presence of chronic conditions based on positive medical history, covering heart diseases, diabetes, hypertension, stroke, lung diseases, and cancer. Depressive symptoms were measured using the eight-item Centre for Epidemiologic Studies Depression Scale (CES-D), which includes depressed mood (depressed, lonely, sad), lack of well-being (reverse-coded happy, enjoying life), and psychomotor retardation (everything an effort, restless sleep, can't get going) (Wang, Shen, \& Hurwicz, 2017). The information on income, health behaviour, depression 
and the presence of chronic diseases (heart diseases, diabetes, hypertension, stroke, lung diseases, and cancer) were updated each wave.

\section{Statistical analysis}

Baseline characteristics (sociodemographic, health behaviour, and health status) were compared across categories of sensory function (hearing impairment only, visual impairment only, and dual sensory impairment) using ordinal chi-square tests for categorical variables and Kruskal-Wallis one-way analysis of variance for numerical variables.

\section{Association between sensory impairment and cognitive function}

Linear mixed models were used to assess the relationship between sensory impairment and cognitive function. These multilevel models consist of sensory impairment at baseline and repeated observations of cognitive function nested within individuals. We analysed the linear mixed models separately for hearing impairment and visual impairment as well as a simultaneous model (single and dual) for sensory impairment. The interaction between sensory impairment and time (the time since baseline) was included in each model to assess the effect of sensory impairment and cognitive decline. In these models we allow a quadratic age effect by including baseline age, time (the time since baseline), baseline age squared, time squared, and the interaction between age and time. The time scale is decade, and the baseline age was centred at the mean. For each type of impairment, we performed two analyses: with simple adjustment (demographic and socioeconomic covariates only) and full adjustment (all covariates). Baseline age, gender, and education are fixed (non-time varying) covariates, while wealth, health behaviour (smoking status, drinking behaviour, and physical exercise) and health related variables (the presence of chronic diseases and depression) are time varying covariates. We further generated the predicted trajectories of cognitive function 
(controlled for all covariates in the linear mixed model) with separate curves for sensory impairment using twoway qfit function in STATA 14.

Longitudinal studies of cognitive ageing, including the HRS, are subject to attrition in which respondents are prone to selective dropout due to death or poor health (Chatfield, Brayne, \& Matthews, 2005). Compared to the completer, the dropout sample in this study tends to be older, had better memory, and had less depressive symptoms (see Appendix 2). Additionally the proportions of women, those with low education background and those with chronic diseases in the dropout sample are higher than those in the sample with complete observations. As ignoring those dropouts can result in bias in the analysis, we tested the sensitivity of our results to attrition by using a joint model (Graham, Ryan, \& Luszcz, 2011; Tampubolon, 2015). In the joint model, the association between the longitudinal and missingness processes is explained by the shared random effects. The random effects $(h()$. below) in the joint model influence both cognitive function, $y$, and attrition, $t$, given these, cognitive function and attrition are independent. A joint model has two parts: the linear mixed model $(f($.$) below) and the survival model ( g($.$) below) with gender, baseline age, time,$ time squared and the random intercepts from the linear mixed model.

$$
L=\int f\left(y_{i} \mid b_{i}, x_{i}\right) g\left(t_{i} \mid b_{i}, x_{i}\right) h\left(b_{i}\right) d b_{i}
$$

We then compared the results of linear mixed model with that of the joint model to assess the robustness of the linear mixed model to attrition.

Association between sensory impairment and the risk of possible CIND and probable dementia 
The multivariate association between sensory function and risk of possible CIND and probable dementia was assessed using a Cox proportional hazard model with year as the time scale. Respondents with prevalent possible CIND and probable dementia at entry into the cohort were excluded from our analyses. In the first analysis, we modelled the relationship between sensory function and risk of possible CIND. Participants were censored as of the wave in which possible CIND was first recorded, dropped out of the study, or Wave 12 (2014), whichever came first. We excluded participants who had probable dementia in the following waves without having possible CIND beforehand. The second analysis modelled the association between sensory function and risk of probable dementia. In this analysis, we censored the participants as of the wave in which probable dementia was first recorded, dropped out of the study, or Wave 12 (2014). The incidence of possible CIND and probable dementia was calculated with a person-wave method using 10-year age groups of the overall study population. As with the linear mixed models, the results were adjusted for age, gender, marital status, education, and income in the first step and additionally for health behaviour (smoking status, drinking behaviour, and physical exercise) and health related variables (the presence of chronic diseases and depression) in the second step. Covariates (sociodemographic variables, health behaviours and health status) were drawn from baseline (the first wave respondents participated the survey). We analysed the Cox proportional hazard models separately for hearing impairment, visual impairment, and both sensory impairments simultaneously. The assumption of proportional hazards was checked graphically using log cumulative hazard plots for outcomes according to the presence of sensory impairment. The linear mixed and Cox proportional hazard models were constructed using STATA 14 and the joint model was performed using Latent Gold 5.1.

\section{Results}


(Table 1 is around here)

The baseline sensory function characteristics of respondents are summarised in Table 1 . The study sample consisted of 19,618 respondents (10,871 women and 8,747 men) aged 57.8 years old on average at baseline. The mean scores in the episodic memory, serial $7 \mathrm{~s}$, and backward counting tests were $11.4,3.9$, and 1.9, respectively. Slightly more than $20 \%$ of respondents were current smokers at baseline, and fewer than half engaged in vigorous physical activity at least three times per week. Approximately $26.4 \%$ of the respondents had one or more sensory impairment $(7.8 \%$ had hearing impairment only, $13.5 \%$ had visual impairment only, and 5\% had both hearing and visual impairments).

Sensory impairment was associated with lower baseline performance on episodic memory and serial 7s tests in the bivariate analysis. Respondents with visual (11.0 words), hearing (10.8 words) and dual sensory impairments (10.2 words) were able to memorise fewer words than those with no impairment (11.6 words). Respondents with visual impairment performed worst (3.5 on average) than other groups in the serial 7s test. Respondents with dual sensory impairments scored an average of 3.9 in the serial $7 \mathrm{~s}$ test, while the mean score of those with no impairment was 4 . Respondents with sensory impairments were on average significantly older, less educated, and more often women than those with no impairment.

\section{Longitudinal association between sensory impairment and cognitive function}

(Figure 1 is around here)

The trajectories of the cognitive scores with different levels of sensory functions are shown in Figure 1. In general, the cognitive trajectories of older adults in the US took the shape of curvilinear trajectories. Figure 1A shows that respondents with better hearing function performed better than those with poorer hearing function over time. Similar patterns are 
illustrated in Figure 1B: respondents with poorer visual function attained lower cognitive scores over time. The dual sensory impairment model reflects a gradation of cognitive trajectories; respondents with a single impairment performed better than those with dual sensory impairment, but not as well as those with no impairment. The difference in cognitive functioning is greater in middle-age than in older age in those three figures is like due to mortality related attrition. The proportion of the observations decreased substantially at older of ages. For example, respondents aged 50-60 years old made $29.6 \%$ of the observations, while only $10.6 \%$ of the observations aged $80-90$ years old.

The results from the linear mixed models are presented in Appendix 3. In the separate analyses, the presence of hearing (coefficient $=-0.62 ; 95 \% \mathrm{CI}=-0.74,-0.50$ ) and visual impairments (coefficient $=-0.79 ; 95 \% \mathrm{CI}=-0.90,-0.68)$ were independently associated with lower cognitive scores after adjustment for age and sociodemographic factors. The association remained significant when all covariates were included in the analysis. Focusing on the dual sensory impairment model, where all potential confounders were included, respondents with single (coefficient $=-0.52 ; 95 \% \mathrm{CI}=-0.62,-0.42$ ) and dual impairments (coefficient $=-0.88 ; 95 \% \mathrm{CI}=-1.07,-0.69)$ scored lower on the cognitive tests than those with no impairment. Focusing on the cognitive trajectories, hearing (coefficient $=0.04 ; 95 \% \mathrm{CI}=-$ $0.05,0.14)$ show no significant association with cognitive decline. Visual impairment $($ coefficient $=-0.26 ; 95 \% \mathrm{CI}=-0.35,-0.17)$ and dual sensory impairments $($ coefficient $=-0.19$; $95 \% \mathrm{CI}=-0.37,-0.02)$ is associated with increased rate of cognitive decline. To deal with attrition, we conducted joint models (Appendix 4). Compared to results of linear mixed models, the association of sensory impairments and cognitive function is stronger in joint models. The absence of substantial differences between the results of linear mixed models and joint models indicated that the results were robust. 
(Table 2 is around here)

(Figure 2 is around here)

(Figure 3 is around here)

During 18 years of follow-up, there were 951 incident probable dementia cases, among whom 91 respondents had hearing impairment, 184 respondents had visual impairment and 184 respondents had dual sensory impairment. The Kaplan-Meier curves for unadjusted rates of incident possible CIND (Figure 2) and dementia (Figure 3) show differences in risk according to the presence of sensory impairment.

Table 3 shows the estimated hazard ratios and 95\% confidence intervals for the development of possible CIND and probable dementia according to sensory function. There was a significant relationship between hearing impairment and the risk of CIND (HR=1.17; 95\% $\mathrm{CI}=1.09,1.26)$ after adjusted with all covariates. Multivariable-adjusted hazard ratios of possible CIND were significantly higher among individuals with visual impairment than those with no impairment $(\mathrm{HR}=1.35 ; 95 \% \mathrm{CI}=1.26,1.44)$. The graded effect of single and dual sensory impairment on the risk of possible CIND was shown in the Model 3. Respondents with single and dual sensory impairment had 30\% ( $\mathrm{HR}=1.30 ; 95 \% \mathrm{CI}=1.23,1.39)$ and $40 \%(\mathrm{HR}=1.38 ; 95 \% \mathrm{CI}=1.25,1.54)$ higher risk of having possible CIND than those with no impairment, respectively.

The relationships between sensory impairment and the risk of probable dementia are shown in Table 3 right pane. With adjustment for demographic and socioeconomic status, the risk of probable dementia was significantly higher for respondents with baseline visual impairment 
$(\mathrm{HR}=1.42 ; 95 \% \mathrm{CI}=1.22,1.64)$. The association between visual impairment and the risk of probable dementia continued to be statistically significant, though reduced $(\mathrm{HR}=1.25 ; 95 \%$ $\mathrm{CI}=1.07,1.46)$ in the fully adjusted model. Compared to the respondents with no sensory impairment, those with single impairment had significantly higher risk of probable dementia $(\mathrm{HR}=1.2 ; 95 \% \mathrm{CI}=1.03,1.4)$.

\section{Discussion}

This long-term prospective study of the US population has two key findings. Firstly, it demonstrated a significant relationship between sensory impairment and higher rates of cognitive decline. Secondly, it shows that sensory impairment was associated with increased risk of possible CIND and probable dementia. Respondents with hearing impairment were at a $17 \%$ higher risk of incident possible CIND. Our study offers new evidence of the relationship between visual impairment and the risk of possible CIND and probable dementia. We found that individuals with vision impairment were at $35 \%$ increased risk of incident possible CIND. Focusing on dementia, individuals with visual impairment had $25 \%$ greater risk of having probable dementia. Life-course models describing risk factors of dementia should now consider visual impairment as an additional potentially modifiable risk. Our study further extends the research and models the joint effects of the two sensory impairments on the risk of possible CIND, showing that an individual with combined hearing and visual impairments has a 38\% higher risk of having possible CIND (HR, 1.38; $95 \% \mathrm{CI}=$ $1.23,1.39)$ than an individual with no sensory impairment.

Prior studies have been few and inconclusive regarding the association between sensory impairments and cognitive decline and dementia. Focusing on cognitive function, one longitudinal study examined 253 individuals aged 45-64 years at baseline and found that hearing impairment was associated with faster cognitive decline over 20 years (Deal et al., 
2015). Dupuis et al. examined at the effect of single and dual sensory impairment on cognitive function as assessed using the Montreal Cognitive Assessment (MoCA) and found that participants with normal hearing and visual functioning were more likely to pass the MoCA (Dupuis et al., 2015). In contrast, Hong et al. demonstrated the lack of association between sensory (visual, hearing, and dual) impairment and cognitive decline among 3654 participants of Blue Eye Mountain Study. Supporting those findings, a study of older people with mild-to-moderate hearing impairment who were fitted with hearing aid $(n=56$; mean age=72.5), and a control group (a hearing-impaired control group without hearing aids; $n=46$; mean age $=74.5$ ) found no improvement of cognitive performance after 12 months (van Hooren et al., 2005). The significant association between sensory impairment and the risk of dementia in this study support previous reviews and epidemiological studies (Albers et al., 2015; Thomson et al., 2017; Deal et al., 2017; Gurgel et al., 2014; Lin et al., 2011). For example, the Health, Aging and Body Composition (Health $\mathrm{ABC}$ ) study found that moderate/severe audiometric hearing impairment was associated with increased $55 \%$ higher risk of incident dementia over 9 years (Deal et al., 2017).

\section{Potential mechanisms}

The literature has proposed several hypotheses. One of them proposed that poor hearing function may confound the cognitive testing. As a telephone examination method, TICS was primarily administered verbally, which possible biased against those with severe hearing impairment (Lindenberger \& Baltes, 1994; Van Boxtel et al., 2001). However, the significant association between sensory impairment and cognitive decline persists among those with visual impairment, which signifies that association is more likely to be explained by other potential mechanisms. Our finding supports the sensory deprivation hypothesis (Lin et al., 2013; Lindenberger \& Baltes, 1994; Wahl \& Heyl, 2003), according to which sensory 
impairment may be causally related to cognitive decline and dementia by means of several potential mechanisms. The first mechanism is that sensory impairment may affect other areas of the brain (Carrera \& Tononi, 2014; Saré, 2016). A study in the US using data from 126 respondents aged 56-86 years old found that the hearing impaired respondents experienced accelerated volume decline in the right temporal lobe and in the entire brain compared to respondents with normal hearing (Lin et al., 2014). This finding was supported by a recent study from the Netherlands that reported that hearing impairment was associated with smaller total brain volume (Rigters et al., 2017).

Alternatively, sensory impairment may have an indirect association with cognition and dementia because it leads to decreased physical activity, lower mood or social isolation. Our results show that the significant relationship between hearing impairment and the risk of dementia diminished after we included health behaviour, depression and health status in the analysis. Salive et al. reported that poorer visual function was related to limitations in physical performance, mobility and daily living activities (Salive et al., 1994) which in turn increased the risk of cognitive impairment and dementia (Laurin et al., 2001; Weuve et al., 2004). The associations between social isolation and both cognition and dementia have been demonstrated in previous work (Bennett, Schneider, Tang, Arnold \& Wilson, 2006; Wilson et al., 2007); one plausible explanation for the link is that poor social networks lead to increased inflammation and glucocorticosteroid levels, which may cause changes in brain structure (Hawkley \& Cacioppo, 2010). Our previous work favours the causal mechanism of sensory impairment and cognition; we have reported that interventions in sensory ability, i.e. cataract surgery and hearing aids, are linked to slower cognitive decline (Maharani, Tampubolon, Nazroo, Dawes, \& Pendleton, 2018; Maharani, Tampubolon, Nazroo, Dawes, \& Pendleton, 2018). Further well-designed studies are needed to examine whether treating visual and hearing impairment can prevent CIND and dementia. 
The common-cause hypothesis, in which both sensory impairment and dementia may be caused by a common underlying pathology such as the generalised effects of ageing or vascular disease, should also be considered (Lindenberger \& Baltes, 1994). Common pathology such as a neurodegenerative processes was found to affect both the eye and brain (Mutlu et al., 2017). Using data from the Australian Longitudinal Study of Ageing (ALSA), a cross-sectional analysis found that almost $80 \%$ of age-related variance in cognitive function was shared with sensory function (Anstey, Luszcz \& Sanchez, 2001). However, the follow up study using longitudinal data of ALSA demonstrated less shared intra-individual variance between hearing and cognitive function (Anstey et al., 2003).

\section{Strengths and limitations of study}

The strengths of our study include a lengthy follow-up period in a nationally representative sample of older adults. The repeated assessment of cognitive function over an 18-year period allowed us to examine the trajectories of cognitive ability among respondents with dissimilar sensory function.

This study has several limitations. Firstly, the TICS method used to define the possible CIND and probable dementia is not equivalent to a clinical diagnostic assessment for dementia. Crimmins et al. evaluated the TICS used in HRS data by comparing it with a subsample in which a detailed neuropsychiatric assessment has been performed in Aging, Demographics, and Memory Study (ADAMS) (Crimmins, Kim, Langa, \& Weir, 2011). They found that 74\% of respondents of HRS were correctly classified into their ADAMS diagnosis when using a multivariate model, but that only $61 \%$ of respondents (including those interviewed by proxy) were correctly classified when using the TICS alone. Other limitation of our study is the use of self-reported measures of hearing and visual function. As the respondents of HRS were enrolled in an epidemiologic survey not focusing on sensory impairment, only subjective 
measurements of sensory function were obtained. The measures used, however, are consistently used in population-based prevalence surveys as they are quick and inexpensive to administer (Liljas et al., 2015; Polku et al., 2015). Self-reported of visual function has been validated in prior studies (Whillans \& Nazroo, 2014). The third limitation of this study is that its observational design prevents us from directly drawing causal inference. Although we adjusted for numerous potential confounders, some residual confounding may still have been present. Finally, we did not have extensive data on covariates such as blood pressure, or lipid measures in all waves used. Both these factors are strongly related to dementia and retinal pathologies.

\section{Conclusions}

This large prospective study of older Americans demonstrated associations between sensory impairment and (i) lower cognitive function over time and (ii) an increased risk of developing dementia. Our results add to the growing body of evidence linking sensory function to optimal brain function, suggesting that maintaining adequate sensory function could contribute to the slowing of cognitive decline as well as the prevention of the onset of dementia among older adults. Hearing and visual impairments are often modifiable, and under treatment of these conditions in older adults is common (Munoz et al., 2000). Proactively identifying hearing and visual impairment then addressing identified impairments may reduce individuals' risk of future cognitive impairment and dementia.

To our knowledge, this is the first study to identify the association of visual impairment and dual sensory impairments with an increased risk of developing probable dementia. We found that visual impairment is associated with higher risk of possible CIND and probable dementia independent of the potential risk factors. Life-course models of dementia risk factors, which already include hearing impairment (Livingston et al., 2017), may now include visual and 
dual sensory impairment to better capture the modifiable risk factors that contribute to dementia. 


\section{References}

Ahmadi-Abhari S., Guzman-Castillo M., Bandosz P., Shipley M. J., Muniz-Terrera G., Singh-Manoux A., ... \& Brunner E. J. (2017). Temporal trend in dementia incidence since 2002 and projections for prevalence in England and Wales to 2040: Modelling study. BMJ, 358, j2856. doi: 10.1136/bmj.j2856.

Albers, M. W., Gilmore, G. C., Kaye, J., Murphy, C., Wingfield, A., Bennett, D. A., . . . \& Devanand, D. P. (2015). At the interface of sensory and motor dysfunctions and Alzheimer's disease. Alzheimer's \& Dementia, 11(1), 70-98. doi: 10.1016/j.jalz.2014.04.514.

Anstey K. J., Luszcz M. A., \& Sanchez L. (2001). A reevaluation of the common factor theory of shared variance among age, sensory function, and cognitive function in older adults. The Journals of Gerontology Series B: Psychological Sciences and Social Sciences, 56, P3-P11. doi: 10.1093/geronb/56.1.P3.

Anstey K. J., Hofer S. M., Luszcz M. A. A Latent Growth Curve Analysis of Late-Life Sensory and Cognitive Function Over 8 Years: Evidence for Specific and Common Factors Underlying Change. Psychology and Aging, 18(4), 714-726. Doi: 10.1037/0882-7974.18.4.714.

Anstey K. J., von Sanden C., Salim A., \& O’Kearney R. (2007). Smoking as a risk factor for dementia and cognitive decline: A meta-analysis of prospective studies. American Journal of Epidemiology, 166, 367-378. doi: 10.1093/aje/kwm116.

Bennett D. A., Schneider J. A., Tang Y., Arnold S. E., \& Wilson R. S. (2006). The effect of social networks on the relation between Alzheimer's disease pathology and level of cognitive function in old people: a longitudinal cohort study. The Lancet Neurology, 5, 406-12. doi: 10.1016/S1474-4422(06)70417-3. 
Carrera E., \& Tononi G. (2014). Diaschisis: past, present, future. Brain, 137, 2408-22. doi: 10.1093/brain/awu101.

Castanho T. C., Amorim L., Zihl J., Palha J. A., Sousa N., \& Santos N. C. (2014). Telephonebased screening tools for mild cognitive impairment and dementia in aging studies: a review of validated instruments. Frontiers in Aging Neuroscience, 6, 1-17. doi: 10.3389/fnagi.2014.00016.

Chatfield, M. D., Brayne, C. E., \& Matthews, F. E. (2005). A systematic literature review of attrition between waves in longitudinal studies in the elderly shows a consistent pattern of dropout between differing studies. Journal of Clinical Epidemiology, 58(1), 13-19. doi: 10.1016/j.jclinepi.2004.05.006.

Crimmins E. M., Kim J. K., Langa K. M., \& Weir D. R. (2011). Assessment of cognition using surveys and neuropsychological assessment: the Health and Retirement Study and the Aging, Demographics, and Memory Study. Journals of Gerontology Series B: Psychological Sciences and Social Sciences, 66, i162-i171. doi:10.1093/geronb/gbr048.

Deal J. A., Betz J., Yaffe K., Harris T., Purchase-Helzner E., Satterfield S., ... \& Health ABC Study Group. (2017). Hearing impairment and incident dementia and cognitive decline in older adults: The Health ABC Study. The Journals of Gerontology: Series A, 72, 703-709. doi: 10.1093/gerona/glw069.

Deal, J. A., Sharrett, A. R., Albert, M. S., Coresh, J., Mosley, T. H., Knopman, D., . . Lin, F. R. (2015). Hearing impairment and cognitive decline: a pilot study conducted within the atherosclerosis risk in communities neurocognitive study. American Journal of Epidemiology, 181(9), 680-690. doi: 10.1093/aje/kwu333. 
Dupuis, K., Pichora-Fuller, M. K., Chasteen, A. L., Marchuk, V., Singh, G., \& Smith, S. L. (2015). Effects of hearing and vision impairments on the Montreal Cognitive Assessment. Aging, Neuropsychology, and Cognition, 22(4), 413-437. doi: $10.1080 / 13825585.2014 .968084$.

Graham, P. L., Ryan, L. M., \& Luszcz, M. A. (2011). Joint modelling of survival and cognitive decline in the Australian Longitudinal Study of Ageing. Journal of the Royal Statistical Society: Series C (Applied Statistics), 60(2), 221-238. doi: j.14679876.2010.00737.x.

Gurgel R. K., Ward P. D., Schwartz S., Norton M. C., Foster N. L., \& Tschanz J. T. (2014). Relationship of hearing loss and dementia: a prospective, population-based study. Otology \& Neurotology: Official publication of the American Otological Society, American Neurotology Society [and] European Academy of Otology and Neurotology, 35, 775. doi: 10.1097/MAO.0000000000000313.

Hawkley L. C., \& Cacioppo J. T. (2010). Loneliness matters: a theoretical and empirical review of consequences and mechanisms. Annals of Behavioral Medicine, 40, 218-27. doi: 10.1007/s12160-010-9210-8.

Hong, T., Mitchell, P., Burlutsky, G., Liew, G., \& Wang, J. J. (2016). Visual impairment, hearing loss and cognitive function in an older population: Longitudinal findings from the Blue Mountains Eye Study. PloS One, 11(1), e0147646. doi: 10.1371/journal.pone.0147646.

Humes, L. E., Busey, T. A., Craig, J., \& Kewley-Port, D. (2013). Are age-related changes in cognitive function driven by age-related changes in sensory processing? Attention, Perception, \& Psychophysics, 75(3), 508-524. doi: s13414-012-0406-9. 
Langa K. M., Kabeto M., \& Weir D. (2010). Report on race and cognitive impairment using HRS in 2010 Alzheimer's disease facts and figures 2010. Alzheimer's Disease Facts and Figures 2010.

Langa K. M., Larson E. B., Crimmins E. M., Faul J. D., Levine D. A., Kabeto M. U., \& Weir D. R. (2017). A Comparison of the Prevalence of Dementia in the United States in 2000 and 2012. JAMA Internal Medicine, 177, 51-58. doi:10.1001/jamainternmed.2016.6807.

Laurin D., Verreault R., Lindsay J., MacPherson K., \& Rockwood K. (2001). Physical activity and risk of cognitive impairment and dementia in elderly persons. Archives of Neurology, 58, 498-504. doi:10.1001/archneur.58.3.498.

Liljas A. E., Wannamethee S. G., Whincup P. H., Papacosta O., Walters K., Iliffe S., ... \& Ramsay S. E.. (2015). Socio-demographic characteristics, lifestyle factors and burden of morbidity associated with self-reported hearing and vision impairments in older British community-dwelling men: a cross-sectional study. Journal of Public Health, 38, e21-e28. doi:10.1093/pubmed/fdv095.

Lin F. R., Ferrucci L., An Y., Goh J. O., Doshi J., Metter E. J., ... \& Resnick S. M. (2014). Association of hearing impairment with brain volume changes in older adults. Neuroimage, 90, 84-92. doi: 10.1016/j.neuroimage.2013.12.059.

Lin F. R., Metter E. J., O’Brien R. J., Resnick S. M., Zonderman A. B., \& Ferrucci L. (2011). Hearing loss and incident dementia. Archives of Neurology, 68, 214-220. doi:10.1001/archneurol.2010.362.

Lin M. Y., Gutierrez P. R., Stone K. L., Yaffe K., Ensrud K. E., Fink H. A., ... \& Study of Osteoporotic Fractures Research Group. (2004). Vision impairment and combined vision and hearing impairment predict cognitive and functional decline in older 
women. Journal of the American Geriatrics Society, 52, 1996-2002. doi: 10.1111/j.1532-5415.2004.52554.x.

Lin, F. R., Yaffe, K., Xia, J., Xue, Q.-L., Harris, T. B., Purchase-Helzner, E., . . . Simonsick, E. M. (2013). Hearing loss and cognitive decline in older adults. JAMA Internal Medicine, 173(4), 293-299. doi: 10.1001/jamainternmed.2013.1868.

Lindenberger U., \& Baltes P. B. (1994). Sensory functioning and intelligence in old age: A strong connection. Psychology and Aging, 9, 339.

Livingston G., Sommerlad A., Orgeta V., Costafreda S. G., Huntley J., Ames D., ... \& Mukadam N. (2017). Dementia prevention, intervention, and care. The Lancet, 390, 2673-734. doi: 10.1016/S0140-6736(17)31363-6.

Maharani A., Piers D., James N., Gindo T., Neil P., on behalf of the Sense-Cog WP1 group. Cataract surgery and age-related cognitive decline: a 13-year follow-up on the English Longitudinal Study of Ageing. PLOS One. Submitted.

Maharani A., Piers D., James N., Gindo T., Neil P., on behalf of the Sense-Cog WP1 group. (2018). Longitudinal relationships between hearing aid use and cognitive function in older Americans. Journal of the American Geriatric Society; 66 (6): 1130-1136. doi: 10.1111/jgs.15363.

Maharani A., Piers D., James N., Gindo T., Neil P., on behalf of the Sense-Cog WP1 group. (2018). Visual and hearing impairments are associated with cognitive decline in older Americans, Britons and Europeans. Age and Ageing. Age and Ageing; 47 (4): 575581. doi: 10.1093/ageing/afy061.

Muñoz B., West S. K., Rubin G. S., Schein O. D., Quigley H. A., Bressler S. B., ... \& the SSE Study Team. (2000). Causes of blindness and visual impairment in a population 
of older Americans: The Salisbury Eye Evaluation Study. Archives of Ophthalmology, 118, 819-25. doi:10.1001/archopht.118.6.819.

Mutlu U., Bonnemaijer P. W. M., Ikram M. A., Colijn J. M., Cremers L. G. M., Buitendijk G. H. S., .. \& Ikram M. K. (2017). Retinal neurodegeneration and brain MRI markers: the Rotterdam Study. Neurobiology of Aging, 60,183-191. doi: 10.1016/j.neurobiolaging.2017.09.003.

Pichora-Fuller, M. K., Kramer, S. E., Eckert, M. A., Edwards, B., Hornsby, B. W., Humes, L. E., . . . \& Mackersie, C. L. (2016). Hearing impairment and cognitive energy: The framework for understanding effortful listening (FUEL). Ear and Hearing, 37, 5S$27 \mathrm{~S}$.

Polku H., Mikkola T. M., Rantakokko M., Portegijs E., Törmäkangas T., Rantanen T., \& Viljanen A. (2015). Self-reported hearing difficulties and changes in life-space mobility among community-dwelling older adults: a Two-year follow-up study. BMC Geriatrics, 15, 121. doi: 10.1186/s12877-015-0119-8.

Prince M., Wimo A., Guerchet M., Ali G. C., Wu Y. T., \& Prina A. M. (2015). World Alzheimer Report 2015. The global impact of dementia. An analysis of prevalence, incidence, cost \& trends; Alzheimer's Disease International: London.

Rigters S. C., Bos D., Metselaar M., Roshchupkin G. V., de Jong R. J. B., Ikram M. A., ... \& Goedegebure A. (2017). Hearing impairment is associated with smaller brain volume in aging. Frontiers in Aging Neuroscience, 9, 2. doi: 10.3389/fnagi.2017.00002.

Salive M. E., Guralnik J., Glynn R. J., Christen W., Wallace R. B., \& Ostfeld A. M. (1994). Association of visual impairment with mobility and physical function. Journal of the American Geriatrics Society, 42, 287-92. doi: 10.1111/j.1532-5415.1994.tb01753.x. 
Saré R. M. (2016). Diaschisis: An Old Concept Brought to New Life. Journal of Neuroscience, 36, 1051-52. doi: 10.1523/JNEUROSCI.4014-15.2016.

Sonnega A, Faul J. D., Ofstedal M. B., Langa K. M., Phillips J. W., \& Weir D. R. (2014). Cohort profile: The Health and Retirement Study (HRS). International Journal of Epidemiology, 43, 576-585. doi: 10.1093/ije/dyu067.

Tampubolon G. Cognitive ageing in Great Britain in the new century: cohort differences in episodic memory. PLoS One 2015, 10, e0144907. doi: 10.1371/journal.pone.0144907.

Tampubolon, G., \& Maharani, A. (2017). When Did Old Age Stop Being Depressing? Depression Trajectories of Older Americans and Britons 2002-2012. The American Journal of Geriatric Psychiatry; 25(11), 1187-1195. doi: 10.1016/j.jagp.2017.06.006.

Thomson RS., Auduong P., Miller A.T., Gurgel R.K. (2017). Hearing loss as a risk factor for dementia: A systematic review. Laryngoscope Investigative Otolaryngology, 2(2), 6979. doi: 10.1002/lio2.65.

Wang Y., Shen H., \& Hurwicz M. (2017). Measuring depressive symptoms with 8-item and 9-item CES-D: Does race/ethnicity matter? Innovation in Aging; 1: 1149-49. doi: 10.1093/geroni/igx004.4196.

Weuve J., Kang J. H., Manson JE, Breteler MM, Ware JH, Grodstein F. Physical activity, including walking, and cognitive function in older women. JAMA 2004;292:1454-61. doi: 10.1001/jama.292.12.1454.

Whillans J., \& Nazroo J. Assessment of visual impairment: The relationship between selfreported vision and 'gold-standard' measured visual acuity. British Journal of Visual Impairment, 32, 236-248. doi: 10.1177/0264619614543532.

World Health Organization, Deafness and hearing loss. Factsheet. 2017. Website: http://www.who.int/mediacentre/factsheets/fs300/en/. 
World Health Organization, Vision impairment and blindness. Factsheet. 2017.Website: http://www.who.int/mediacentre/factsheets/fs282/en/.

Wilson R. S., Krueger K. R., Arnold S. E., Schneider J. A., Kelly J. F, Barnes LL, .... \& Bennet D.A. (2007). Loneliness and risk of Alzheimer disease. Archives of General Psychiatry, 64, 234-40. doi: 10.1001/archpsyc.64.2.234.

Yaffe K. Chronic medical disease and cognitive aging: Toward a healthy body and brain. (2013). Oxford University Press.

Yamada Y., Denkinger M. D., Onder G., Henrard J. C., van der Roest H. G., Finne-Soveri H., ... \& Topinkova E. (2015). Dual sensory impairment and cognitive decline: the results from the Shelter Study. Journals of Gerontology Series A: Biomedical Sciences and Medical Sciences, 71, 117-123. doi: 10.1093/gerona/glv036. 
List of tables 
Table 1 Descriptive characteristics of baseline study sample by sensory impairment status

\begin{tabular}{|c|c|c|c|c|c|c|}
\hline & $\begin{array}{c}\text { Total } \\
\mathrm{N}=19,618\end{array}$ & $\begin{array}{c}\text { No impairment } \\
\qquad \mathrm{N}=\mathbf{1 4 , 4 2 9}\end{array}$ & $\begin{array}{c}\text { Hearing impairment } \\
\text { only } \\
\mathrm{N}=\mathbf{1 , 5 4 8}\end{array}$ & $\begin{array}{c}\text { Visual impairment } \\
\text { only } \\
\mathrm{N}=\mathbf{2 , 6 5 7}\end{array}$ & $\begin{array}{l}\text { Dual impairments } \\
\qquad \mathrm{N}=984\end{array}$ & P Value \\
\hline Episodic memory, mean (SD) & $11.4(2.8)$ & $11.6(2.8)$ & $10.8(2.7)$ & $11,0(2.6)$ & $10.2(2.5)$ & $<0.001$ \\
\hline Serial $7 \mathrm{~s}$, mean $(\mathrm{SD})$ & $3.9(1.3)$ & $4.0(1.3)$ & $4.0(1.2)$ & $3.5(1.5)$ & $3.9(1.5)$ & $<0.001$ \\
\hline Backward count, mean (SD) & $1.9(0.3)$ & $1.9(0.2)$ & $1.9(0.3)$ & $1.9(0.3)$ & $1.9(0.3)$ & 0.659 \\
\hline Age, mean (SD) & $57.8(6.2)$ & $57.6(6.2)$ & $59.4(6.7)$ & $57.6(6.1)$ & $58.5(6.6)$ & $<0.001$ \\
\hline Female, n (\%) & $10,871(55.4)$ & $8,310(57.5)$ & $468(30.2)$ & $1,619(60.9)$ & $474(48.1)$ & $<0.001$ \\
\hline Education & & & & & & $<0.001$ \\
\hline Less than high school, $\mathrm{n}(\%)$ & $4,065(20.7)$ & $2,350(16.2)$ & $363(23.4)$ & $922(34.7)$ & $430(43.6)$ & \\
\hline High school, n (\%) & $5,878(29.9)$ & $4,287(29.7)$ & $503(32.4)$ & $803(30.2)$ & $285(28.9)$ & \\
\hline Some college, n (\%) & $9,675(49.3)$ & $7,792(54.0)$ & $682(44.0)$ & $932(35.0)$ & $269(27.3)$ & \\
\hline Smoking behaviour & & & & & & $<0.001$ \\
\hline Non-smoker, n (\%) & $8,257(42.0)$ & $6,390(44.2)$ & $518(33.4)$ & $1,011(38.0)$ & $338(34.3)$ & \\
\hline Past smoker, n (\%) & $7,264(37.0)$ & $5,314(36.8)$ & $702(45.3)$ & $889(33.4)$ & $359(36.4)$ & \\
\hline Current smoker, n (\%) & $4,097(20.8)$ & $2,725(18.8)$ & $328(21.1)$ & $757(28.4)$ & $287(29.1)$ & \\
\hline $\begin{array}{l}\text { Drinking behaviour (unit/week), mean } \\
\text { (SD) }\end{array}$ & $2.9(8.6)$ & $2.8(8.8)$ & $3.5(8.4)$ & $2.6(7.0)$ & $3.6(10.0)$ & $<0.001$ \\
\hline Depression score, mean (SD) & $1.3(1.8)$ & $1.0(1.6)$ & $1.4(1.8)$ & $2.1(2.2)$ & $2.7(2.4)$ & $<0.001$ \\
\hline Vigorous exercise, $\mathrm{n}(\%)$ & $9,404(47.9)$ & $7,319(50.7)$ & $772(49.8)$ & $991(37.2)$ & $322(32.7)$ & $<0.001$ \\
\hline \multicolumn{7}{|l|}{ Presence of chronic diseases } \\
\hline Diabetes mellitus, n (\%) & $2,389(12.1)$ & $1,446(10.0)$ & $196(12.6)$ & $536(20.1)$ & $211(21.4)$ & $<0.001$ \\
\hline Stroke, $\mathrm{n}(\%)$ & $616(3.1)$ & $324(2.2)$ & $57(3.6)$ & $162(6.0)$ & $73(7.4)$ & $<0.001$ \\
\hline Heart diseases, $\mathrm{n}(\%)$ & $2,425(12.3)$ & $1,467(10.1)$ & $283(18.2)$ & $455(17.1)$ & $220(22.3)$ & $<0.001$ \\
\hline Hypertension, $\mathrm{n}(\%)$ & $7,552(38.4)$ & $5,214(36.1)$ & $621(40.1)$ & $1,235(46.4)$ & $482(48.9)$ & $<0.001$ \\
\hline Cancer, n (\%) & $1,341(6.8)$ & $979(6.7)$ & $115(7.4)$ & $167(6.2)$ & $80(8.1)$ & 0.19 \\
\hline Lung disease, $\mathrm{n}(\%)$ & $1,037(5.2)$ & $574(3.9)$ & $121(7.8)$ & $225(8.4)$ & $117(11.8)$ & $<0.001$ \\
\hline
\end{tabular}


Development of possible CIND, $\mathrm{n}(\%)$

$5,772(26.9)$

$3,743(24.2)$

$538(31.5)$

$1,054(34.4)$

$437(36.3)$

$<0.001$

Development of probable dementia, $n$

$1,764(8.2)$

$982(6.3)$

$158(9.2)$

$406(13.2)$

$218(18.1)$ 
Table 2 Association between sensory impairment and the risk of possible CIND and probable dementia

Risk of possible CIND

Risk of probable dementia

\begin{tabular}{|c|c|c|c|c|c|c|c|c|}
\hline & \multicolumn{2}{|c|}{ Simple adjustment } & \multicolumn{2}{|c|}{ Full adjustment } & \multicolumn{2}{|c|}{ Simple adjustment } & \multicolumn{2}{|c|}{ Full adjustment } \\
\hline & HR $(95 \%$ CI $)$ & P Value & HR $(95 \%$ CI $)$ & P Value & HR $(95 \%$ CI $)$ & P Value & HR $(95 \%$ CI $)$ & P Value \\
\hline \multicolumn{9}{|c|}{ Presence of hearing impairment } \\
\hline No hearing impairment & 1.00 & reference & 1.00 & reference & 1.00 & reference & 1.00 & reference \\
\hline Hearing impairment & $\begin{array}{c}1.240(1.097 \\
1.267)\end{array}$ & $<0.001$ & $\begin{array}{c}1.179(1.097 \\
1.267)\end{array}$ & $<0.001$ & $\begin{array}{c}1.180(0.996 \\
1.397)\end{array}$ & 0.054 & $\begin{array}{c}1.088(0.915 \\
1.293)\end{array}$ & 0.337 \\
\hline \multicolumn{9}{|c|}{ Presence of visual impairment } \\
\hline No visual impairment & 1.00 & reference & 1.00 & reference & 1.00 & reference & 1.00 & reference \\
\hline Visual impairment & $\begin{array}{c}1.473(1.385 \\
1.566)\end{array}$ & $<0.001$ & $\begin{array}{c}1.351(1.267 \\
1.441)\end{array}$ & $<0.001$ & $\begin{array}{c}1.420(1.226 \\
1.645)\end{array}$ & $<0.001$ & $\begin{array}{c}1.255(1.074 \\
1.466)\end{array}$ & 0.004 \\
\hline \multicolumn{9}{|c|}{ Presence of sensory impairment } \\
\hline No sensory impairment & 1.00 & reference & 1.00 & reference & 1.00 & reference & 1.00 & reference \\
\hline Single sensory impairment & $\begin{array}{r}1.394(1.312, \\
1.480)\end{array}$ & $<0.001$ & $\begin{array}{r}1.309(1.231, \\
1.393)\end{array}$ & $<0.001$ & $\begin{array}{r}1.316(1.136, \\
1.523)\end{array}$ & $<0.001$ & $\begin{array}{r}1.197(1.029, \\
1.392)\end{array}$ & 0.020 \\
\hline
\end{tabular}


Abbreviations: CIND, Cognitive Impairment Non Dementia; HR, hazard ratio; CI, confidence interval.

Notes: Simple adjustment: adjusted for age, gender, marital status, education and wealth. Full adjustment: adjusted for age, gender, marital status, education, wealth, smoking and drinking behaviour, physical exercise, depression scores and number of comorbidities 


\section{List of Figures}

Figure 1 Trajectories of summary cognitive scores of HRS participants by presence of sensory impairment

Figure 2 Kaplan-Meier curves for unadjusted rates of possible CIND by hearing function (top panel), visual function (middle panel), and both (bottom panel).

Figure 3 Kaplan-Meier curves for unadjusted rates of probable dementia by hearing function (top panel), visual function (middle panel), and both (bottom panel). 